\title{
ESTRATÉGIA DE PRODUÇÃO: UMA ABORDAGEM SOBRE SUA OPERACIONALIZAÇÃO EM PROPRIEDADES RURAIS PRODUTORAS DE SOJA
}

\author{
Camyla Piran Leitner Stiegler \\ Adelice Minetto Sznitowski**
}

\begin{abstract}
RESUMO: O processo de planejamento da estratégia de produção compreende certos níveis de planejamento. De ordem macro para micro tem-se em primeiro plano a estratégia corporativa; dela faz parte a estratégia competitiva que abrange as prioridades competitivas. A partir das prioridades competitivas, juntamente às decisões estruturais e infraestruturais, forma-se a estratégia de produção. Foi com foco nesse nível de decisão que o estudo se desenvolveu tendo como objeto produtores de soja do município de Campo Novo do Parecis-MT. Para isso foi realizada pesquisa de campo com aplicação de questionários aos produtores rurais acerca da relevância das decisões estruturais e infraestruturais para o planejamento de safra. No estudo buscou-se: a) identificar o perfil das propriedades rurais b) verificar quais são as decisões adotadas pelos produtores e c) elencar os tipos de decisões considerando as decisões estruturais e as decisões infraestruturais para os produtores de soja. Os resultados encontrados evidenciam que todos os agricultores, em seu processo decisório da função produção, levam em conta os fatores estruturais e infraestruturais, sendo possível verificar que as decisões quanto às tecnologias são as mais relevantes nos fatores estruturais e, gestão da qualidade, planejamento e controle da produção e organização se destacam nas decisões infraestruturais.
\end{abstract}

PALAVRAS-CHAVE: Produção agrícola; Decisões estruturais e infraestruturais; Gestão de operações.

\section{PRODUCTION STRATEGY: AN APPROACH ON OPERATIONABILITY IN SOYBEAN PLANTATIONS}

ABSTRACT: Production strategy process comprises several levels of planning. Corporative strategy comprises competition strategy with competitive priorities

\footnotetext{
Doutora em Engenharia de produção, Docente permanente da Universidade do Estado de Mato Grosso UNEMAT do Curso de Administração Campus Universitário de Nova Mutum (MT), Brasil.

** Doutora em Administração, Docente permanente da Universidade do Estado de Mato Grosso - UNEMAT do Curso de Administração Campus Universitário de de Tangará da Serra-MT, Brasil

E mail: adeliceadm@gmail.com
} 
which, in their turn, coupled to structural and infrastructural decisions, provide production strategy. Current study was developed with the above focus at such decision level, aiming at soybean producers in the municipality of Campo Novo do Parecis MT Brazil. A field research was undertaken with questionnaires to rural producers on the relevance of structural and infrastructural decisions for harvest planning. Current study identified the profile of producers, verified producers' decisions and listed the types of decisions, taking into account the structural and infrastructural decisions for soybean producers. Results show that, in their decisions on functional production, all producers take structural and infrastructural factors into account. It has been verified that decisions on technology are more relevant in structural factors. Quality Management, Planning and Control of Production and Organization are highlighted in infrastructural decisions.

KEY WORDS: Agricultural production; Structural and infrastructural decisions; Operation management.

\section{INTRODUÇÃO}

No contexto mundial atual o Brasil situa-se como celeiro agrícola. Possui 22\% das terras agricultáveis do mundo (RODRIGUES, 2006), além de fazer uso de alta tecnologia, tornando o agronegócio brasileiro um setor moderno, eficiente e competitivo. O Estado de Mato Grosso no contexto nacional tem expressiva contribuição nos resultados obtidos pelas cadeias produtivas de grãos, como cita o Instituto Mato-grossense de Economia Agropecuária (IMEA, 2012). A agricultura mato-grossense ganhou espaço após os anos de 1980, pela expansão da fronteira agrícola com a vinda dos agricultores da região Sul do país que trouxeram técnicas de produção (CAMPOS, 2011). A colonização foi possível diante do baixo valor das terras, das linhas especiais de crédito criadas pelo governo e as condições climáticas de relevo, isso fez com que os produtores se deslocassem para o Estado de Mato Grosso (BERNARDES, 1997).

Segundo o Ministério da Agricultura, Pecuária e Abastecimento (MAPA, 2014), o aumento da produtividade está associado aos avanços tecnológicos, ao manejo e à eficiência dos produtores e a garantia de mercado, pois a soja é um componente essencial na fabricação de ração animal e com uso crescente na alimentação humana, dentre outros. 
Para Pozzobon, Löbler e Silveira (2006), a evolução do desempenho do setor agrícola é resultado da modernização da atividade rural, mas as transformações decorrentes dessa modernização acarretaram novas exigências no gerenciamento das propriedades agrícolas. Menciona-se ainda que nesses locais pouco são usadas práticas de gestão e estratégias. Nantes e Scarpelli (2012) acrescentam que pouca atenção foi dedicada à nova realidade comercial e gerencial nas mais diversas áreas dessas empresas, em especial, àquelas relacionadas ao processo produtivo. É neste contexto que se inserem as decisões estratégicas.

Planos e ações relacionados à função operações sustentam aà estratégia competitiva da empresa. A Estratégia de Produção ou Operações, segundo Hayes e Wheelwright (1984), tem como tarefa principal direcionar uma organização na montagem e no alinhamento dos recursos produtivos para que seja possível executar a estratégia competitiva e alcançar os resultados desejados. Para que isso aconteça, é preciso a formulação das decisões estratégicas, e também é necessário, antes de tudo, definir as áreas/prioridades que serão o foco da atenção da função operações para prover vantagem competitiva à organização.

Após definidas as prioridades a serem trabalhadas no processo produtivo, faz-se necessário estabelecer medidas relacionadas às denominadas áreas de decisão. Há duas categorias de área de decisão: áreas de Decisões Estruturais e áreas de Decisões Infraestruturais. Para Hayes e Wheelwright (1984), as áreas de decisões denominadas estruturais são caracterizadas dessa forma pelo impacto de longo prazo e pelo grande aporte de capital necessário para sua implantação e, em consequência, são difíceis de serem desfeitas ou revertidas. Quando a categoria de decisões infraestruturais é considerada, tratam-se relativamente de decisões de menor impacto e de menor custo de implementação, embora possam ser consideradas do mesmo modo como estratégicas.

Há pesquisas envolvendo decisões estratégicas em diversos segmentos, porém ainda há escassez de estudos sobre decisões estratégicas voltadas especificamente para a sojicultura. Com isso percebeu-se a necessidade de conhecer em quais categorias de decisão os produtores de soja investem maiores recursos ou esforços para alcançar seus objetivos estratégicos, direcionando este estudo a investigar as propriedades rurais de Campo Novo do Parecis-MT. Assim, o objetivo 
principal foi identificar quais as decisões estruturais e infraestruturais têm maior relevância na tomada de decisão estratégica para a produção de soja dos agricultores num dos maiores municípios produtores de grãos do Estado de Mato Grosso.

\section{REFERENCIAL TEÓRICO}

\subsection{ESTRATÉGIA DE PRODUÇÃO}

Estratégia de Produção (EP), de acordo com Slack e Lewis (2009), é o padrão de decisões que determina as competências de longo prazo da função operações, conciliando os requisitos do mercado com os processos e recursos operacionais da empresa, para que eles forneçam base sólida para a vantagem sustentável da organização. Para Chase et al (2006, p. 97) "a EP pode ser vista como parte de um processo de planejamento que coordena os objetivos/metas operacionais com os objetivos mais amplos das organizações".

As categorias de decisões podem ser agrupadas, conforme a sua natureza, em dois grandes grupos: estruturais e infraestruturais. Na Figura 01 é ilustrada a hierarquia da estratégia, detalhando a divisão das categorias de decisão da estratégia de produção, de maneira a facilitar análises minuciosas das decisões apropriadas.

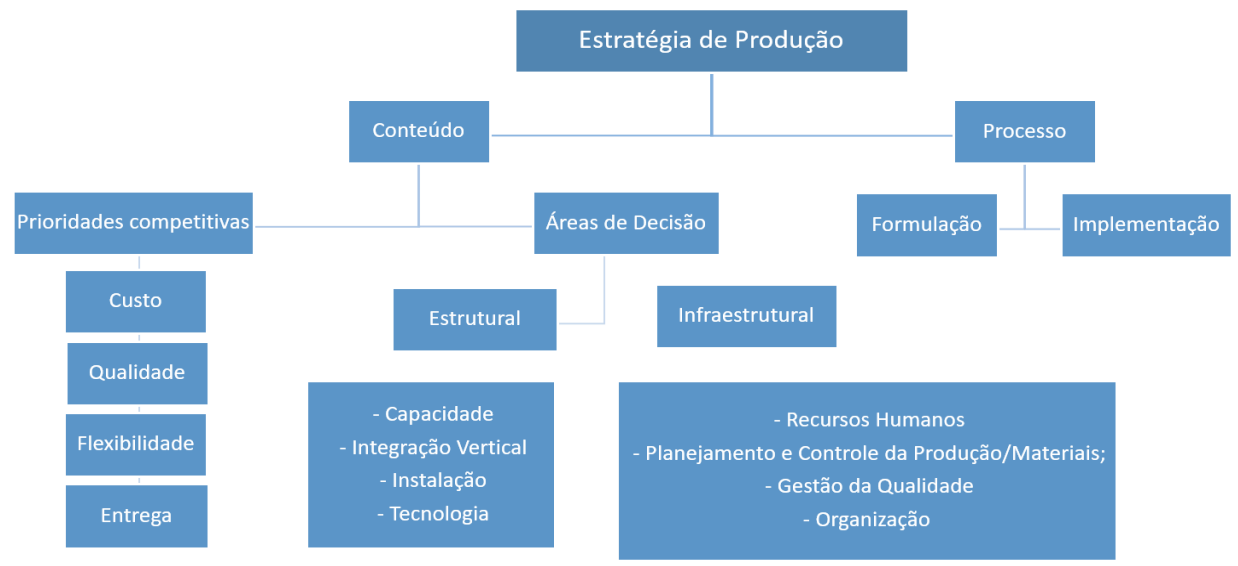

Figura 1. Hierarquia da estratégia de produção

Fonte: adaptada de Horte, Lindbergs e Tunalvs (1987) 
As categorias dos blocos de decisão estruturais e infraestruturais são passíveis de mudança de acordo com o mercado, devendo ser consistentes e bem definidas, pois toda a função produção da empresa irá se moldar a estas decisões. Nessa perspectiva, Boyer e Lewis (2002) citam que o conjunto consistente de decisões será responsável por sustentar a estratégia de produção, e estas, serão abordadas na sequência.

\subsection{DECISÕES ESTRUTURAIS}

Hayes e Wheelwright (1984) apresentam as áreas de decisão como meios de sistematizar a estratégia e obter excelência na manufatura. Na sequência, primeiramente, serão abordados os fatores que compõem os tipos de decisões estruturais.

a) Instalações: para Paiva, Carvalho e Fensterseifer (2004, p.45) "instalações se relacionam às decisões sobre localização geográfica, tipo de processo produtivo, volume e ciclo de vida".

Para investimentir nas instalações da empresa é necessário analisar o tamanho da unidade produtiva, sua localização geográfica e o grau de especialização do produto (HAYES; WHEELWRIGHT, 1984). Pires (1995) menciona que outros fatores também devem ser analisados no planejamento de investimento de instalações: logística de abastecimento (matéria-prima) e de distribuição (produto acabado) e a disponibilidade de custo de mão-de-obra.

b) Capacidade: está relacionada às decisões de instalações, sendo determinada pela planta, equipamentos e recursos humanos (PAIVA; CARVALHO; FENSTERSEIFER, 2004). Capacidade é a análise relativa ao que será produzido e também quanto será produzido, balizada em termos de necessidade de mercado e possibilidade tecnológica disponível (WHEELWRIGHT, 1984). Para Hayes e Wheelwright (1984), as decisões inerentes a esta categoria tem estreita ligação com a demanda de mercado e, portanto, as empresas têm que decidir se trabalharão com sua capacidade acima, abaixo ou acompanhando a demanda.

O dimensionamento adequado da capacidade permite obter vantagem competitiva substancial, pois os seus recursos serão melhores disponibilizados, já o 
mal dimensionamento poderá resultar na perda de clientes, em função da sobrecarga de capacidade produtiva e também acarretar custo elevado pelas capacidades ociosas (SLACK et al., 1997).

c) Tecnologia: a implantação de tecnologia inclui fatores como escolhas de novos equipamentos, de automação e de integração no processo produtivo (HAYES; WHEELWRIGHT, 1984) e a adoção de sistemas de informação para a gestão da produção (PIRES, 1995).

d) Integração Vertical: Barros Neto (1999) se refere à integração vertical como o relacionamento com clientes e fornecedores, assim como o posicionamento nesta mesma relação. Podendo então se basear nesses dois fatores, obtendo a proporção exata de qual pode sucumbir à terceirização de seus produtos, conhecimento do potencial de seus fornecedores, além do prazo e qualidade exigida de seus clientes. Em essência, é uma questão entre fabricar os produtos ou fornecer serviços, ou ainda comprá-los de outros. Apesar de estarem baseadas na análise da lucratividade de se fazer ou comprar, essas decisões são, em grande medida, de natureza estratégica (KARLÖF, 1994).

\subsection{DECISÕES INFRAESTRUTURAIS}

De acordo com Slack, Chambers e Johnston (2008, p. 101), "decisões infraestruturais são as que influenciam a força do trabalho de uma organização, as atividades de planejamento, controle e melhoria”. Complementa que as melhores e mais caras tecnologias só serão eficazes se a produção possuir infraestrutura adequada para governar a produção diária fazendo com que a mesma funcione.

Para Nogueira (2002), as áreas de decisões infraestruturais são consideradas mais táticas por envolverem decisões contínuas que estão relacionadas a aspectos operacionais do negócio, sendo listadas na sequência:

a) Recursos humanos: atuam sobre as políticas definidas e existentes nas empresas, a fim de atingir as metas organizacionais (PAIVA; CARVALHO; FENSTERSEIFER, 2004); são diferenciais competitivos entre empresas (PIRES, 1995). Para Barros

Neto (1999), a categoria de decisões em recursos humanos está relacionada com recrutamento, seleção, contratação, treinamento, promoção, remuneração, avaliação, transferência, demissão etc. 
b) Gestão da qualidade: o gerenciamento dessa decisão deve estar pautado na definição das metas e formas de controle da qualidade dos produtos e processos da empresa, deve-se atribuir responsabilidades, definir quais serão as ferramentas e sistemas usados; definir os programas de treinamento a serem instituídos (PIRES, 1995). A gestão da qualidade estabelece políticas, critérios de inspeção de materiais, avaliações e reprovações dos produtos produzidos e avaliação de fornecedores (WHEELWRIGHT, 1984).

c) Planejamento e controle da produção (PCP): refere-se ao modo de como a empresa se organiza em termos de previsão e programação dos recursos na produção; são as decisões referentes à maneira de atuar sobre os meios de produção para aumentar a eficiência e cuidar para que os objetivos de produção sejam alcançados (WHEELWRIGHT, 1984). Para Barros Neto (1999), a maior preocupação do PCP é a entrega do produto/serviço nas condições préestabelecida pelo cliente.

d) Organização (forma de organizar): as decisões relativas a esse fator envolvem principalmente a estrutura organizacional, os níveis hierárquicos e a organização do trabalho na empresa. Oliveira (1998) afirma que a estrutura organizacional é uma importante ferramenta no desenvolvimento e implementação do plano organizacional das empresas, portanto, ela deve ser delineada de acordo com os objetivos e estratégias estabelecidos.

\subsection{DECISÕES ESTRUTURAIS E INFRAESTRUTURAIS NA PRODUÇÃO AGRÍCOLA}

Para Hansson e Ferguson (2011, p. 110), "A produção agrícola se insere de forma intensa na economia global, consequentemente, muitas empresas agrícolas estão a ser confrontadas com desafios difíceis na manutenção de uma posição competitiva". King et. al. (2010, p. 563) destacam que "compreender como competir numa economia global, inserido num contexto agrícola dinâmico [...] é um desafio chave para os decisores do agronegócio".

No caso da gestão de propriedades rurais, a adequação dessa prática permite que tais empreendimentos se mantenham num ambiente de alta competitividade. A gestão nessas organizações pode ser dividida em dois aspectos: 
a) processos produtivos desenvolvidos internamente e, b) relações comerciais entre organizações - ambiente externo. As atividades inerentes a cada um desses aspectos têm relevância para manter a competitividade no agronegócio, o qual tem uma dinâmica diferenciada em relação a outros setores da economia (CALLADO; CALLADO, 2009).

Ainda sobre a gestão, Canziani (2002) cita que os empreendimentos rurais não são geridos com agilidade e eficiência que os permita serem competitivos. Embora haja consciência de tais deficiências e sua ligação positiva entre de técnicas de gestão e o sucesso das propriedades rurais, a área de gestão nesses locais não recebe a atenção que deveria.

No entanto, como nos demais tipos de organizações, as unidades de produção do agronegócio precisam elaborar estratégias para competirem no mercado global (BUSCH; BAIN, 2004). Dobbins, Boehlje e Miller (2002) apoiam tal afirmação por entenderem que nesse contexto exige das propriedades rurais a formulação de estratégias de negócio, relacionando novos planos com combinações de produto, mercado e estrutura de finanças e, por conseguinte, devem elaborar estratégias funcionais, tais como a estratégia de operações.

Essa "fábrica a céu aberto" tem como características diversas condições que interferem nas estratégias das operações produtivas das propriedades rurais, tais como as condições de solo, clima, relevo, disponibilidade de mão de obra etc., bem como as restrições de recursos (terra, capital e trabalho) dos produtores rurais (OSAKI, 2012).

Em função dessas especificidades, a atividade agrícola é vista como um setor no qual ocorrem estratégias emergentes, não estruturadas e raramente decorrentes de outras, como cita Rathamann et al (2007). Por essas razóes, que na busca por competitividade, as propriedades rurais carecem de novos modelos gerenciais e operacionais, sendo orientados por padrões de qualidade e a redução dos custos de produção. (NANTES; SCARPELLI, 2012).

Tendo em vista as especificidades do mercado de grãos, as decisões estratégicas da área operacional são as mais delicadas e recorrentes por parte do agricultor, e estão relacionadas à combinação das atividades para produzir além de um produto e, nesse caso, é necessário decidir se adquire ou aluga as máquinas e equipamentos, decisão esta inserida na categoria de decisões estruturais (OSAKI, 2012). 
Ligada à aquisição de novas máquinas com alta tecnologia, está a necessidade de capacitar a mão de obra que vai operar nelas. A remuneração desse pessoal tem relação direta com seus conhecimentos e habilidades (LAZZAROTO; HIRAKURI, 2010). Isso se enquadra no conjunto de decisões infraestruturais da EO. O Quadro 01 elenca algumas atividades do processo produtivo de grãos relativo às diversas áreas das categorias de decisões.

Quadro 1. Framework comparativo entre os conceitos do conteúdo da estratégia de operações consagrado na literatura e os respectivos entendimentos para a produção agrícola

\begin{tabular}{|c|c|c|}
\hline \multicolumn{3}{|c|}{ DECISÕES ESTRUTURAIS } \\
\hline CATEGORIA & $\begin{array}{c}\text { ENTENDIMENTO TEÓRICO PARA } \\
\text { INDUSTRIAS E EMPRESAS DE SERVIÇOS }\end{array}$ & $\begin{array}{c}\text { ENTENDIMENTO TEÓRICO PARA PRODUÇÃO } \\
\text { DE GRÃOS }\end{array}$ \\
\hline CAPACIDADE & $\begin{array}{l}\text { Tamanho da unidade produtiva, posse de } \\
\text { maquinários, ajustes frente a demanda }\end{array}$ & $\begin{array}{l}\text { Balizada pela quantidade de área disponivel para o plantio } \\
\text { (própria ou arrendada) e pela variedade de produtos e tipos } \\
\text { de sementes a serem utilizadas. }\end{array}$ \\
\hline INSTALAÇÕES & $\begin{array}{l}\text { Localização geográfica, grau de especialização do } \\
\text { produto, logistica de abastecimento e distribuição }\end{array}$ & Áreas em diferentes regiões, estrutura de armazenagem, \\
\hline TECNOLOGIA & $\begin{array}{c}\text { Máquinas, equipamentos, sistemas de informação } \\
\text { gerencial }\end{array}$ & Mecanização do plantio, tratos culturais e cotheita \\
\hline INTEGRAÇÃO VERTICAL & \begin{tabular}{|c|}
$\begin{array}{c}\text { Sucontratações, terceirização, dominio de mais de } \\
\text { um segmento da cadeia de produção }\end{array}$ \\
\end{tabular} & $\begin{array}{l}\text { Opções de ampliação do dominio das operações à jusante e } \\
\text { à montante da cadeia de produção }\end{array}$ \\
\hline \multicolumn{3}{|c|}{ DECISÕES INFRAESTRUTURAIS } \\
\hline CATEGORIA & $\begin{array}{c}\text { ENTENDIMENTO TEÓRICO PARA } \\
\text { INDUSTRIAS E EMPRESAS DE SERVIÇOS }\end{array}$ & $\begin{array}{c}\text { ENTENDIMENTO TEÓRICO PARA PRODUÇÃO } \\
\text { DE GRÃOS }\end{array}$ \\
\hline GESTÃO DA QUALIDADE & $\begin{array}{l}\text { Planejamento do produto, controle do processo, } \\
\text { inspeções do produto final }\end{array}$ & $\begin{array}{c}\text { Controle da qualidade do grão, aplicações de insumos, para } \\
\text { ganho de produtividade, processos de inspeção dos } \\
\text { produtos }\end{array}$ \\
\hline RECURSOS HUMANOS & $\begin{array}{c}\text { Politicas de remuneração, de treinamento, clima } \\
\text { organizacional, cumprimento das normas de } \\
\text { segurança }\end{array}$ & $\begin{array}{l}\text { Politicas de remuneração, Contratação de mão de obra, } \\
\text { treinamentos técnicos, NR } 31\end{array}$ \\
\hline $\begin{array}{l}\text { PLANEJAMENTO E CONTROLE DA } \\
\text { PRODUÇÃO }\end{array}$ & $\begin{array}{c}\text { Roteiros de produção, flexibilidade de alteração da } \\
\text { programação }\end{array}$ & $\begin{array}{l}\text { Planejamento ano/safra, roteiro dos talhões para plantio, } \\
\text { redefinição da programação devido as varíveis não } \\
\text { controláveis (climáticas, biologicas) }\end{array}$ \\
\hline ORGANIZAÇÃO & Delegação de funções, niveis hierárquivos & $\begin{array}{c}\text { Estilos de liderança, Definições e ajustes de niveis } \\
\text { hierárquicos }\end{array}$ \\
\hline $\begin{array}{l}\text { REACIONAMENTO COM } \\
\text { FORNECEDORES }\end{array}$ & $\begin{array}{c}\text { Seleção de fornecedores, tipos de relacionamento, } \\
\text { acordos e parcerias }\end{array}$ & $\begin{array}{l}\text { Financiamento da produção, parcerias em ações } \\
\text { organizacionais, treinamentos, etc. }\end{array}$ \\
\hline
\end{tabular}

Fonte: Leitner e Alves Filho (2014)

Todas as categorias elencadas no Quadro 1 são de fundamental importância para os resultados que o agricultor busca. Ao encontro dessa afirmação, Ferraz et al (1995) destacam a importância das propriedades rurais elaborarem um 
bom planejamento e controle dos processos produtivos. Observa-se, então, com base no exposto neste estudo, que a estratégia de operações se aplica à gestão das propriedades rurais e, portanto, pode ser adotada para auxiliar as ações dos agricultores na produção de grãos.

\section{MATERIAL E MÉTODOS}

Quanto à abordagem, a pesquisa se classifica como quantitativa, de caráter exploratório utilizando-se do levantamento tipo survey de corte transversal (crosssectional), seguindo as recomendações de Bryman (1989); Malhotra (2001) e Hair Jr. et al. (2005). A pesquisa se baseou em dados parciais coletados para tese de doutorado com o tema "Estratégias de operações de propriedades produtoras de grãos do Núcleo Oeste do Estado de Mato Grosso". Para a definição da quantidade de propriedades a serem investigadas, observou-se o banco de dados da Associação de Produtores de Soja e Milho de Mato Grosso (APROSOJA-MT) que possui 225 produtores associados pertencentes ao município de Campo Novo do Parecis-MT. Desses, optou-se por pesquisar 10,1\% da população, índice considerado adequado para Malhotra e Grover (1998), dado o caráter exploratório do estudo.

Assim, a pesquisa foi realizada em 24 propriedades rurais produtoras de soja no município de Campo Novo do Parecis-MT por meio de questionário estruturado com perguntas fechadas e seguindo o padrão Likert para as respostas. O questionário foi dividido em dois blocos, sendo: 1) perfil das propriedades, prioridades competitivas e estratégias competitivas e 2) com questões referentes às áreas de decisões estruturais e infraestruturais, com base no autor Wheelwright (1984), que permitiram identificar os investimentos ou esforços dispendidos pelos produtores rurais nas referidas áreas de decisão.

Antes da aplicação do questionário foi realizado um pré-teste em agosto de 2014 com 12 produtores da região produtora denominada 'Núcleo Oeste da APROSOJA-MT' e mais dois pesquisadores da área de Estratégia de Operações para validação quanto à facilidade de compreensão do instrumento. Assim, com o préteste realizado, foram feitas algumas alterações como (a) reformular as alternativas 
das questões sobre tamanho da propriedade (bloco 01), (b) colocar opções de mais tipos de cultivares (bloco 01), (c) acrescentar outras formas de comercialização (bloco 01) e (d) diminuir os valores das opções de respostas de investimentos relacionados à capacidade (bloco 02). Com tais ajustes, considerou-se o questionário apto para utilização.

Os questionários finais foram aplicados em setembro de 2014, alguns por e-mail (survey), porém a taxa de retorno não atingiu o número considerado válido (somente 13 responderam). Assim, os demais (11) foram aplicados em evento da Aprosoja-MT, o $9^{\circ}$ Circuito Aprosoja realizado no dia 03 de setembro de $2014 \mathrm{em}$ Campo Novo do Parecis-MT, evento este já consolidado entre os sojicultores. Os contatos foram feitos com base na lista fornecida por essa entidade, tomando o cuidado de evitar a duplicidade de respostas, assim os respondentes à medida que participavam da pesquisa eram eliminados da lista. Dos participaram da pesquisa, 18 se identificaram como proprietários, quatro gerentes, um arrendatário e um denominado de "outro" (podendo ser agrônomo e/ou filho do proprietário). Os dados obtidos junto a esse grupo de agricultores foram analisados de forma qualitativa, apresentados em forma de quadros e textos.

\section{RESULTADO E DISCUSSÃO}

\subsection{PERFIL DAS PROPRIEDADES PRODUTORAS}

Todas as propriedades agrícolas pesquisadas, além do tamanho - são grandes propriedades (média de 2.800 ha) e, como demonstrado na Figura 2, têm como principal produto a soja. 


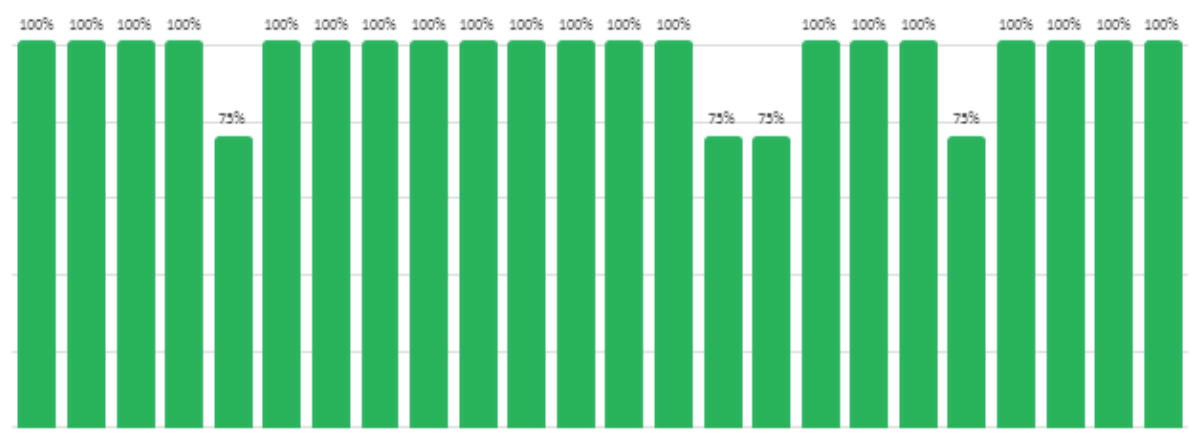

Percentual da área total cultivada com soja

Figura 2. Percentual da área da propriedade correspondente ao cultivo de soja, nas 24 propriedades pesquisadas

Fonte: Elaborado pelas autoras (2014)

A forma de cultivo é via plantio direto, típica dos grandes produtores que cultivam grandes extensões. Também é comum esses agricultores fazerem segunda safra, principalmente do milho, como fora constatado por Sant'Ana (2010) e Osaki (2012). No presente estudo, verificou-se que, além do milho (79\% das propriedades), outros grãos são cultivados na segunda safra, como segue $67 \%$ optaram por girassol e, $29 \%$ semearam milho pipoca. Importante ressaltar que nas culturas de segunda safra, o produtor não necessariamente opta apenas por uma cultura, podendo plantar milho e milho pipoca, milho pipoca e girassol ou milho e girassol.

Ao diversificar a área de cultivo como multiproduto em duas safras no mesmo ano agrícola o produtor busca reduzir os riscos inerentes à produção, pois com a diversificação podem ser diminuídas as oscilações de receita e, assim, criar um fluxo de caixa mais estável (ZEN; BRAGATO; SPERS, 2005; OSAKI, 2012). Além da questão econômica, a diversificação também se dá com a intenção de rotacionar a cultura principal (trabalhando com outra cultura durante a entressafra), buscando a redução de danos causados por pragas e doenças, para manter o nível de fertilidade do solo e, ainda, evitar a erosão como constatou Osaki (2012).

Outra característica referente ao perfil das propriedades diz respeito ao número de funcionários que pode variar em função do tamanho da propriedade. 
No entanto, a maioria (45,8\%) possuía entre um e dez funcionários, contratados conforme a demanda de serviços, que oscila em determinados períodos como pósplantio e pós-colheita. Quanto ao tamanho das propriedades, a maior parte $(87,5 \%)$ é grandes áreas, isto é, aproximadamente 2.800 ha. O porte da propriedade é uma das primeiras características observadas pelos produtores para o planejamento de safra, uma vez que é em função do tamanho do empreendimento rural que são tomadas outras decisões (como números de funcionários, máquinas etc.). Uma propriedade de grande porte é considerada aquela que tem área acima de 1.500 ha (LEI n $\left.{ }^{0} 8.629\right)$.

Não somente o tamanho da propriedade, mas também a posse da terra é levada em consideração no planejamento da safra, pois diante da demanda crescente de soja os produtores podem optar por adquirir terras ou arrendá-las. Na safra 2010/2011, 75\% das terras eram próprias e 25\% arrendadas. Já na safra 2013/2014, houve oscilação na posse da terra equivalente a $2 \%$, reduzindo o percentual de plantio em terras próprias e aumentando o mesmo percentual de produção em terras arrendadas.

Quanto ao tipo de soja cultivada, se convencional ou transgênica (geneticamente modificada) prevalece a soja convencional, a qual é mais comercializada no mercado externo (exportação); já a transgênica é comercializada no mercado interno. Os grãos produzidos são vendidos por intermédio dos principais clientes existentes no mercado. Com relação aos principais clientes, Vieira Junior et al (2006) e Silva, (2008) comentam que há um segmento denominado "atacadista" que estabelece relações comerciais diretamente com os produtores, comprando, armazenando e/ou movimentando a produção para a indústria de esmagamento, ou para o mercado externo de grãos, de forma simultânea ou isolada. Fazem parte desse grupo as tradings, as cooperativas, as corretoras e os armazenadores. Sendo no caso do grupo pesquisado, as tradings são suas principais clientes, ou seja, para quem vendem sua produção.

Sabendo que a maior parte dos produtores comercializam os grãos produzidos via tradings ${ }^{3}$ certas exigências mercadológicas devem ser cumpridas. Uma delas é a certificação dos produtos. O mercado exige conformidade dos

3 Trading - empresa comercial que atua como intermediária entre empresas fabricantes e compradoras, numa operaçã̃o de exportação ou de importação. 
produtos (no caso a soja) face às especificações previstas para atender as diferentes exigências dos mercados chinês e europeu. Enquanto o primeiro se preocupa com a quantidade de matéria-prima para a indústria, o mercado europeu atenta aos atributos de qualidade, aspectos de segurança e sanidade do alimento e normas de não transgênicos como constatado também por Zylbersztajn (2013).

Constatou-se que boa parte $(54,2 \%)$ possui algum tipo de certificação. Os produtores detêm certificações para aqueles produtos com demanda de exportação, ou seja, a soja, e por esse fator a certificação de produto não transgênico é primordial para comercialização.

\subsection{DECISÕES ADOTADAS PELOS PRODUTORES}

As decisões adotadas pelos produtores rurais pesquisados estão divididas em decisões estruturais e infraestruturais. As decisões estruturais estão subdivididas em capacidade, instalações, tecnologias e integração vertical ao qual será analisada a seguir.

a) Decisões estruturais: $\mathrm{Na}$ Tabela 1 é relatada a capacidade das propriedades rurais do município de Campo Novo do Parecis-MT.

Tabela 1. Decisões de investimentos em capacidade das propriedades rurais de Campo Novo do Parecis - MT, safra 2013/14

\begin{tabular}{|c|c|c|c|c|c|c|c|c|}
\hline CAPACIDADE & $\begin{array}{c}\text { Nenhum } \\
\text { investimento }\end{array}$ & $\begin{array}{l}\text { Até R\$ } \\
500 \mathrm{mil}\end{array}$ & \begin{tabular}{|c|} 
Acima de \\
$\mathrm{R} \$ 500$ mil a \\
$\mathrm{R} \$ 1$ milhão
\end{tabular} & $\begin{array}{c}\text { Acima de } R \$ \\
1 \text { milhão a } \\
\mathrm{R} \$ 3 \text { milhões }\end{array}$ & $\begin{array}{l}\text { Acima de } R \$ \\
R \$ 3 \text { milhões a } \\
\text { R\$ } 5 \text { milhões }\end{array}$ & $\begin{array}{l}\text { Acima de } R \$ \\
R \$ 5 \text { milhões a } \\
R \$ 10 \text { milhões } \\
\end{array}$ & $\begin{array}{l}\text { Acima de } \\
10 \text { milhões }\end{array}$ & TOTAL \\
\hline $\begin{array}{c}\text { Aumento da área plantada por } \\
\text { arrendamento }\end{array}$ & $63 \%$ & $8 \%$ & $17 \%$ & $13 \%$ & -- & -- & -- & $100 \%$ \\
\hline $\begin{array}{l}\text { Aumento da área plantada } \\
\text { com aquisição de áreas }\end{array}$ & $67 \%$ & $4 \%$ & $13 \%$ & $8 \%$ & -- & -- & $8 \%$ & $100 \%$ \\
\hline $\begin{array}{l}\text { Aumento do número de } \\
\text { funcionários }\end{array}$ & $38 \%$ & $54 \%$ & $8 \%$ & -- & -- & -- & -- & $100 \%$ \\
\hline
\end{tabular}

Fonte: Elaborado pelas autoras (2014)

No que refere a investimentos envolvendo decisões estruturais e estas a respeito de capacidades, percebe-se maior percentual (66,5\%) de agricultores que 
não investiram nesse quesito, no entanto, os que investiram realizaram dispêndios significativos, acima de 10 milhões para 8,4\% dos produtores. Já para áreas arrendadas, os valores máximos ficaram em até 3 milhões. Maior percentual dos agricultores investiu em funcionários, o que tem relação direta com a aquisição e arrendamento de áreas, no entanto, por se tratar de um item que demanda menor valor por contratação, os investimentos foram de até 500 mil reais. Em relação a investimentos em capacidade, Costa et al (2011) citam que esta precisa ser vista como fundamental para a produção de commodities $^{4}$, deve ser considerada como uma estratégia importante, haja vista que ganhos de capacidade induzem economias de escala. Na Tabela 2 são apresentados dados relativos às instalações das propriedades rurais pesquisadas.

Tabela 2. Decisões de investimentos em instalações nas propriedades rurais do município de Campo Novo do Parecis - MT na safra 2013/2014

\begin{tabular}{|c|c|c|c|c|c|c|c|c|}
\hline INSTALAÇÕES & $\begin{array}{c}\text { Nenhum } \\
\text { investimento }\end{array}$ & $\begin{array}{l}\text { Até R\$ } \\
500 \text { mil }\end{array}$ & $\begin{array}{c}\text { A cima de } \\
\mathrm{R} \$ 500 \\
\text { mil à } \mathrm{R} \$ \\
1 \text { milhão }\end{array}$ & $\begin{array}{l}\text { Acima de } \\
\text { R \$ } 1 \\
\text { milhão à } \\
\text { R\$3 } \\
\text { milhões }\end{array}$ & $\begin{array}{l}\text { Acima de } \\
R \$ 3 \\
\text { milhões à } \\
R \$ 5 \\
\text { milhões }\end{array}$ & $\begin{array}{l}\text { A cima de } \\
\text { R\$5 } \\
\text { milhões à } \\
\text { R\$ } 10 \\
\text { milhões }\end{array}$ & $\begin{array}{c}\text { Acima de } \\
10 \\
\text { milhões }\end{array}$ & TOTAL \\
\hline $\begin{array}{c}\text { Área dentro do } \\
\text { Estado de Mato } \\
\text { Grosso }\end{array}$ & $57 \%$ & $8 \%$ & $17 \%$ & $8 \%$ & -- & -- & $8 \%$ & $100 \%$ \\
\hline $\begin{array}{c}\text { Área dentro do } \\
\text { Estado de Mato } \\
\text { Grosso }\end{array}$ & $88 \%$ & - & $4 \%$ & $4 \%$ & $4 \%$ & -- & -- & $100 \%$ \\
\hline $\begin{array}{l}\text { Instalação de silos } \\
\text { e/ou armazém na } \\
\text { propriedade }\end{array}$ & $54 \%$ & $9 \%$ & $12 \%$ & $8 \%$ & $9 \%$ & $8 \%$ & -- & $100 \%$ \\
\hline
\end{tabular}

Fonte: Elaborado pelas autoras (2014)

Observou-se que a maior parte dos produtores de Campo Novo do ParecisMT não investiu em instalações dentro do Estado do MT (58,2\%), nem buscou novas fronteiras agrícolas produzindo em outros Estados (87,4\%), ou em silos e armazéns na propriedade $(54,1 \%)$. Embora o maior percentual não tenha investido, não podem ser desconsiderados os investimentos que ocorreram, tanto dentro do Estado (41,8\%) e também 12,6\% na compra de áreas fora do Estado. Destacam-se também os investimentos em armazéns e silos, um fator que carece de investimentos de forma geral. Na Tabela 3 são apresentados os investimentos em algum tipo de

4 Commodity: produto "in natura", cultivado ou de extração mineral, que pode ser estocado por certo tempo, sem perda sensível de suas qualidades, como suco de laranja congelado, soja, trigo, prata ou ouro. (WEERSMA; BATISTA, 2002) 
tecnologia por parte dos agricultores.

Tabela 3. Decisões de investimentos em tecnologia das propriedades rurais do município de Campo Novo do Parecis - MT safra 2013/2014

\begin{tabular}{|c|c|c|c|c|c|c|c|c|}
\hline TECNOLOGIA & $\begin{array}{c}\text { Nenhum } \\
\text { investimento }\end{array}$ & $\begin{array}{l}\text { Até R\$ } \\
500 \mathrm{mil}\end{array}$ & $\begin{array}{c}\text { Acima de } \\
R \$ 500 \text { mil a } \\
R \$ 1 \text { milhão }\end{array}$ & $\begin{array}{c}\text { Acima de } \mathrm{R} \$ \\
1 \text { milhão a } \\
\mathrm{R} \$ 3 \text { milhões }\end{array}$ & $\begin{array}{c}\text { Acima de } \mathrm{R} \$ \\
\mathrm{R} \$ 3 \text { milhôes a } \\
\mathrm{R} \$ 5 \text { milhões }\end{array}$ & \begin{tabular}{|c|} 
Acima de $\mathrm{R} \$$ \\
$\mathrm{R} \$ 5$ milhôes a \\
$\mathrm{R} \$ 10$ milhôes
\end{tabular} & $\begin{array}{l}\text { Acima de } \\
10 \text { milhões }\end{array}$ & TOTAL \\
\hline $\begin{array}{c}\text { Tecnologias para } \\
\text { acompanhamento dos fatores } \\
\text { clima e solo }\end{array}$ & $25 \%$ & $67 \%$ & $4 \%$ & $4 \%$ & -- & -- & -- & $100 \%$ \\
\hline $\begin{array}{c}\text { Sistema de informação para } \\
\text { gerencias as açōes da } \\
\text { produção, custos, estoques, } \\
\text { etc. }\end{array}$ & $38 \%$ & $54 \%$ & $8 \%$ & - & - & - & -- & $100 \%$ \\
\hline $\begin{array}{c}\text { Tecnologias para controle de } \\
\text { pragas e doenças }\end{array}$ & $13 \%$ & $46 \%$ & $33 \%$ & $8 \%$ & -- & -- & -- & $100 \%$ \\
\hline $\begin{array}{c}\text { Máquinas e equipamentos para } \\
\text { plantio e colheita }\end{array}$ & - & $25 \%$ & $33 \%$ & $25 \%$ & $4 \%$ & $13 \%$ & -- & $100 \%$ \\
\hline
\end{tabular}

Fonte: Elaborado pelas autoras (2014)

Investimentos em tecnologias na agricultura permitem reduzir o custo de produção e aumentar os ganhos, como observam Pinto Vieira et al (2007). A respeito dos investimentos nessa categoria, os dados da pesquisa demonstram que todos os produtores investiram em algum tipo de tecnologia. No entanto, os maiores investimentos foram em tecnologias para o controle de pragas (87.4\%) e máquinas e equipamentos para colheita (100\%). O valor gasto no primeiro grupo de tecnologias foi entre 500 mil a 3 milhões de reais. Para o segundo, de 500 mil a 10 milhões de reais. Um percentual um pouco menor, porém, não desprezível, foi investido em tecnologias para acompanhamento dos fatores de clima e solo $(74,8 \%)$ e sistemas de informação voltados à gestão (62,5\%).

Valores estes que ficaram entre 500 mil a 3 milhões de reais e 500 mil a 1 milhão de reais respectivamente.

Por fim, o último item considerado dentro das decisões estruturais é a integração vertical, tendo em vista que a decisão de verticalização por parte da empresa permite diminuir os custos de efetuar transações entre duas ou mais etapas do processo produtivo e desta forma obter maiores retornos (COSTA et al., 2011). Nessa perspectiva, os dados apontam que os produtores de soja pesquisados $(33,3 \%)$ 
adquirem às vezes produtos diretamente do fabricante. Em relação à ampliação de silos e/ou armazéns 41,70\% disseram nunca ter ampliado, enquanto que 41,70\% terceirizam esporadicamente a colheita. Isso ocorre pela rotatividade de produção feita pelos agricultores diversificando o tipo de grão a ser cultivado.

b) Decisões infraestruturais: a ocorrência de investimentos nessa categoria, a qual é composta pelas subcategorias: gestão da qualidade, gestão de pessoas, planejamento e controle da produção, organização, relacionamento com fornecedores, será a seguir apresentada.

A gestão da qualidade é um dos fatores importantes para os produtores, pois a maioria vende seus produtos para o mercado externo, e por isso precisa atender determinados padrões de qualidade e para isso precisa investir em ações nesse sentido. Assim, definem-se padrões para inspeção de insumos (que contribui para a garantia da qualidade dos grãos e para a produtividade da lavoura). Sobre isso, a maior parte dos pesquisados $(29,2 \%)$ disse que investiram raramente ou às vezes, $16,6 \%$ investem frequentemente, $12,50 \%$ sempre investiram e somente $12,50 \%$ dos produtores não investiram.

Quanto à manutenção preventiva das máquinas e equipamentos, a maioria (66,6\%) investiu. Na utilização de normas técnicas (manuais, fichas técnicas, planejamento de safra) no plantio e colheita, 45,8\% dos agricultores fizeram investimentos. Sobre a inspeção do produto final (classificação), também. Investir na gestão da qualidade permite acompanhar as atividades de produção e garantir o controle efetivo dos processos, a diminuição do desperdício e acompanhar as atividades de prevenção. Além disso, os produtores de commodities buscam determinadas certificações, pois a posse de um certificado de qualidade pode representar o acesso a novos nichos de mercado ou caracterizar, até mesmo uma estratégica de diferenciação dos produtos (SANTOS; MACEDO; RAMOS, 2008).

No que se refere à gestão de pessoas nas propriedades rurais de Campo Novo do Parecis-MT, verificou-se que 37,5\% dos produtores sempre investiram em saúde e segurança do trabalho. Sobre o sistema de recompensa baseada na produtividade da lavoura, a maioria $(41,7 \%)$ já investiu, bem como investem em qualificação e treinamento dos funcionários (37,50\%), e em programas de benefícios para os funcionários $(29,20 \%)$. 
Em relação ao planejamento e controle da produção nesses locais, os maiores investimentos foram no planejamento das atividades de plantio, tratos culturais e colheita perfazendo um percentual de 87,5\%. Para controle das atividades de plantio, tratos culturais e colheita $79,2 \%$ dos produtores sempre investiram, bem como no gerenciamento da compra de insumos para a safra 2013/14 (83,4\%). Já em controle de estoques $58,30 \%$ sempre fizeram investimentos.

A respeito da organização das propriedades rurais, sobre a mudança no estilo de liderar, observou-se que respostas divergentes, ou seja, $50 \%$ dos produtores disseram que mudam às vezes, enquanto que 20,80\% estão frequentemente mudando. Já 12,50\% dos afirmaram que sempre mudam, 12,5\% disseram nunca mudar e 4,2\% raramente.

E por último apresentam-se as informações sobre a relação dos produtores rurais com os fornecedores. Identificou-se que conforme a quantidade adquirida de insumos, o fornecedor oferece vantagens como forma de conquistar o cliente (produtor rural). Nesse sentido, 37,5\% dos produtores recebem incentivos para o desenvolvimento de novos produtos e apoio para melhorar a produtividade da lavoura. Quanto a cursos e capacitações disponibilizados pelos fornecedores, 37,5\% afirmaram receber às vezes esse tipo de incentivo e 20,9\% disseram receber sempre ou frequentemente.

As ações relativas à gestão da qualidade planejadas e executadas pelos fornecedores também são oferecidas aos produtores, mas 37,50\% afirmaram receber raramente e $20,90 \%$ nunca receberam.

No que tange ao financiamento da lavoura pelos fornecedores de insumos, $25 \%$ dos produtores sempre utilizam, enquanto que 20,90\% nunca utilizaram/ utilizam às vezes/utilizam frequentemente. Sobre financiar a lavoura via tradings, constatou-se que 79,3\% nunca fizeram, utilizam raramente ou às vezes; enquanto que $20 \%$ utilizam frequentemente ou sempre. Financiamentos das lavouras por parte das cooperativas, $66,6 \%$ dos produtores não usam e 33,40\% dos produtores fazem uso dessa modalidade às vezes ou raramente. 


\subsection{IMPORTÂNCIA DAS DECISÕES}

Com os dados obtidos na pesquisa foi possível fazer uma avaliação das decisões estruturais e infraestruturais relevantes para os produtores rurais do município de Campo Novo do Parecis-MT. Observa-se que 62\% dos produtores deram baixa importância para investimentos de capacidade e $88 \%$ para as decisões de instalações. Já a tecnologia para a maior parte (70\%) dos agricultores foi tida como de grande importância. Na Tabela 4 são demonstrados os percentuais obtidos em cada categoria de decisão estratégica.

Tabela 4. Avaliação das decisões estruturais e infraestruturais dos produtores rurais do município de Campo Novo do Parecis - MT, setembro/2014

\begin{tabular}{c|c|c|c}
\hline FATORES & $\begin{array}{c}\text { GRANDE } \\
\text { IMPORTÂNCIA }\end{array}$ & $\begin{array}{c}\text { MÉDIA } \\
\text { IMPORTÂNCIA }\end{array}$ & $\begin{array}{c}\text { BAIXA } \\
\text { IMPORTÂNCIA }\end{array}$ \\
\hline Capacidade & $16 \%$ & $22 \%$ & $62 \%$ \\
\hline Instalações & $2 \%$ & $10 \%$ & $88 \%$ \\
\hline Tecnologia & $\mathbf{7 0} \%$ & $10 \%$ & $20 \%$ \\
\hline Integração Vertical & $55 \%$ & $15 \%$ & $30 \%$ \\
\hline Gestão da Qualidade & $\mathbf{8 0} \%$ & $8 \%$ & $12 \%$ \\
\hline Gestão de Pessoas & $\mathbf{6 0} \%$ & $15 \%$ & $25 \%$ \\
\hline Planejamento e Controle da & $\mathbf{8 0} \%$ & $10 \%$ & $10 \%$ \\
\hline Produção & $\mathbf{8 0} \%$ & $10 \%$ & $10 \%$ \\
\hline Organização & $45 \%$ & $35 \%$ & $20 \%$ \\
\hline Relação com Fornecedores & \multicolumn{2}{|c|}{}
\end{tabular}

Fonte: Elaborado pelas autoras (2014)

Em relação à Tabela 4, destacam-se as decisões consideradas de grande importância para a maioria dos agricultores, como sendo: primeiramente gestão da qualidade, planejamento e controle da produção e as decisões sobre a estrutura organizacional (organização) têm grande importância para 80\% deles; gestão de pessoas para 66\% dos agricultores; integração vertical com 55\%. Por fim, as decisões quanto ao relacionamento com fornecedores também têm grande importância para $45 \%$ dos produtores. Importante mencionar que as decisões estruturais envolvem altos investimentos, por consequência, são realizadas com menor frequência. Isso significa dizer, também, que as decisões em capacidade e instalações podem ter 
ocorrido em maior volume nas safras anteriores (2010/2011, 2011/2012, 2012/2013).

\section{CONSIDERAÇÕES FINAIS}

Em relação ao objetivo desta pesquisa - identificar quais decisões estruturais e infraestruturais são consideradas pelos produtores de soja do município Campo Novo do Parecis-MT, constatou-se que tanto as decisões estruturais quanto infraestruturais são levadas em consideração pelos produtores, sendo elas interdependentes no processo de tomada de decisão. Contudo, na safra 2013/2014, nas decisões estruturais, os maiores investimentos foram na categoria tecnologia, em especial, nas tecnologias para o controle de pragas (87.4\%) e máquinas e equipamentos para colheita (100\%). Esse resultado não significa que as decisões em instalações, capacidade e integração vertical tenham sido menosprezadas pelos produtores, todavia, a ordem de valores a serem investidos nessas categorias é alta, e podem ter sido realizados em safras anteriores.

Em relação às decisões infraestruturais, investimentos em gestão da qualidade, planejamento e controle da produção e organização foram considerados de maior importância, demonstrando preocupação dos gestores com os resultados alcançados nas operações produtivas (planejamento e controle para garantia da qualidade, com estrutura organizacional alinhada aos princípios organizacionais).

Os resultados encontrados evidenciam que todos os agricultores, em seu processo decisório da função produção, levam em conta os fatores estruturais e infraestruturais, sendo possível verificar que as decisões quanto às tecnologias são as mais relevantes nos fatores estruturais e, gestão da qualidade, planejamento e controle da produção e organização se destacam nas decisões infraestruturais.

Assim, os resultados apresentados contribuem para o avanço do conhecimento voltado à gestão das propriedades rurais pelo fato de apresentar os elementos envolvidos no processo decisório quanto ao planejamento da safra de soja, considerando que a teoria utilizada - estratégia de produção - foi desenvolvida no meio industrial, porém pode se perceber sua aplicação num contexto diferenciado, 
isto é, na agricultura. Além disso, entende-se que este estudo também contribuirá para a adaptação do constructo estratégia de produção às empresas rurais, como sugerido por Leitner e Alves Filho (2014), contribuindo para o avanço da ciência administrativa, engenharias e cadeias produtivas de grãos.

Com relação à limitação do estudo, menciona-se o fato de envolver um único município, podendo ampliar as pesquisas para áreas mais abrangentes. Bem como para outras culturas representativas, haja vista que o Estado de Mato Grosso é o maior produtor de grãos e também há escassez voltada para as unidades de produção "dentro da porteira".

Por fim, considera-se que este trabalho poderá ser útil para efeitos de correlação/comparação com os estudos futuros, possibilitando entender e analisar decisões estratégicas de outras unidades de produção em outros locais somando esforços à discussão da estratégia de produção em empreendimentos rurais.

\section{REFERÊNCIAS}

APROSOJA. Projeto Referência. Disponível em: $<$ http://www.aprosoja.com.br/projeto/projeto-referencia/> Acesso em: 03 maio 2014.

BARROS NETO, J. P. Proposta de um modelo de formulação de estratégias de produção para pequenas empresas de construção habitacional. 1999. 326f. Tese (Doutorado em Administração) - Universidade Federal do Rio Grande do Sul, 1999.

BATALHA, M. O. (Org.). Introdução à engenharia de produção. Rio de Janeiro: Elsevier, 2008.

BERNARDES, J. A. As estratégias do capital no complexo sojífero. In: ENCUENTRO DE GEÓGRAFOS DE AMÉRICA LATINA, 1997. Anais...Buenos Aires, Argentina, 1997. Disponível em: <http://observatoriogeograficoamericalatina.org.mx/egal6/Geografiasocioeconomica/Geografiaagricola/382.pdf > . Acesso em: 27 mar. 2013

BOYER, K.; LEWIS, M. Competitive Priorities: investigating the need for trade-offs in operations strategy. Production and operations Management, v. 11, n. 1, p. 9-19, 2002. 
BRYMAN, A. Research methods and organization studies. London: Unwin Hyman, 1989. p. 283. Disponível em: <http://books.google.com/books?hl=en\&lr=\&id= ImKWWmxclgC\&oi $=$ fnd $\& p g=P P 1 \& d q=$ Research + methods + and + organization + studies\&ots $=$ nthCbnGclH\&sig $=$ bAs2P-_fWH7jf2MIO_bHLR8wwCY $>$. Acesso em: 2 abr. 2013.

BUSCH, L.; BAIN, C. New! Improved? The Transformation of the Global Agrifood System. Rural Sociology, v. 69, n. 3, p. 321-346, set. 2004. Disponível em: $<\mathrm{http}: / / \mathrm{www}$.ingentaselect.com/rpsv/cgi-bin/cgi?ini $=$ xref\&body $=$ linker\&reqdoi $=10.1526 / 0036011041730527>$. Acesso em: 2 abr. 2013.

CALLADO, A. A. C.; CALLADO, A. L. C. Gestão de custos rurais: comparando práticas entre distintos polos de produção agroindustriais do estado de Pernambuco. Revista Contemporânea de Economia e Gestão, v. 7, n. 2, p. 65-74, 2009.

CAMPOS, M. C. Modernização da agricultura, expansão da soja no Brasil e as transformações sócio espaciais no Paraná. Revista Geografar, v. 6, n. 1, p. 161-191, 2011. Disponível em: <www.ser.ufpr.br/geografar> . Acesso em: 2 abr. 2013.

CANZIANI, José Roberto Fernandes. Assessoria administrativa a produtores rurais no Brasil. 2001. 224f. Tese. (Doutorado em Ciências) - Escola Superior de Agricultura "Luiz de Queiroz", Universidade de São Paulo, São Paulo. 2001.

CHASE, R. B.; et al. Administração da produção para vantagem competitiva. 10. ed. Porto Alegre, RS: Bookman, 2006.

COSTA, M. D. et al. Strategies Adopted by Agro-Industry Complex of Soybean Players in Paraguay. Custos e agronegócio on line, v. 7, n. 2, p. 107-119, 2011. Disponível em: <http://www.custoseagronegocioonline.com.br/numero2v7/competitividade soja soybean.pdf?origin $=$ publication_detail $>$. Acesso em: 16 maio 2014 .

DOBBINS, C.; BOEHLJE, M.; MILLER, A. Farmers as Plant Managers \& General Managers: which hat do you wear. West Lafayette: [s.n.], 2002.

FLEURY, P.F.; PROENÇA, A. Competitividade industrial e a gerência estratégica de 
operações. Revista de Administração, São Paulo, v. 28, n. 2, 1993.

HANSSON, H.; FERGUSON, R. Factors influencing the strategic decision to further develop dairy production: a study of farmers in central Sweden. Livestock Science, v. 135, n. 2-3, p. 110-123, 2011.

HAIR, J. F. et al. Análise multivariada de dados. 6. ed. Porto Alegre, RS: Bookman, 2009.

HAYES, R. H.; WHEELWRIGHT, S. C. Restoring our competitive edge: competing through manufacturing. New York: John e Wiley, 1984.

HORTE, S. A.; LINDBERGS, P. e TUNALVS, C. manufacturing strategic in Sweden. International Journal Production Research, London, v. 25, n. 11, p. 1573-1586, 1987. Disponivel em: < http://cert-id.com.br/certification/rtrs/> Acesso em: 10 nov. 2014.

IMEA. Agronegócio em Mato Grosso. Cuiabá - MT, Brasil. 2012. [s.n.]. Disponível em: www.imea.com.br/upload/pdf/...2012_09_13_Apresentacao_MT.pd...>.Acesso em: 24 out. 2014 .

KARLÖF, B. Conceitos básicos de administração. São Paulo: Nobel, 1994.

KING, Robert P.; BOEHLJE, Michael; COOK, Michael L.; SONKA, Steven T. Agribusiness economics and management. American Journal of Agricultural Economics, v. 92 , n. 2, p. 554-570, 2010.

LAZZAROTTO, J; HIRAKURI, M. Evolução e perspectivas de desempenho econômico associadas com a produção de soja nos contextos mundial e brasileiro. Londrina: EMBRAPA-Soja, 2010. Disponível em: < http://garoupa.cnpso.embrapa.br/ download/Doc319_3ED.pdf>. Acesso em: 5 abr. 2013.

LEITNER, C.; ALVES FILHO, A. Conjecturas e proposições sobre as estratégias de produção em propriedades produtoras de grãos. ENCONTRO NACIONAL DE ENGENHARIA DE PRODUÇÃO, ENEGEP, 36., Curitiba 2014. Disponível em: < http://www. 
abepro.org.br/biblioteca/enegep2014_TN_STO_201_138_26101.pdf > . Acesso em: 14 jan. 2015.

MALHOTRA, N. K. Pesquisa de marketing: uma orientação. [S.l.]: Bookman Companhia, 2006. Disponível em:<http://books.google.com.br/books?id=FtdIFOgTP8UC > . Acesso em: 10 nov. 2014.

MAPA. Exportação Soja brasileira 2013. [s.n.], 2014. Disponível em: < http:// www.agricultura.gov.br/dwagrostat/seg_dwagrostat.principal_dwagrostat $>$. Acesso em: 10 nov. 2014.

MOREIRA, D. A. Administração da produção e operações. São Paulo: Thomson Learning, 2006.

NANTES, J. F.; SCARPELLI, M. Elementos de gestão na produção rural. In: BATALHA, M. O. (Org.). Gestão agroindustrial. 3. ed. São Paulo: Atlas, 2012. p. 629-664.

NOGUEIRA, E. Empresas fabricantes de revestimentos cerâmicos e a gestão de seus sistemas produtivos: a proposição de um modelo. Tese de Doutorado, FGV/EASP. São Paulo, 2002. Disponível em:<http:/bibliotecadigital.fgv.br/dspace/ handle/10438/4452?show $=$ full $>$. Acesso em: 05 abr 2014.

OLIVEIRA, D. de P.R. de. Sistemas, organização e métodos: uma abordagem gerencial. 10. ed. São Paulo: Atlas, 1998.

OSAKI, M. Gestão financeira e econômica da propriedade rural com multiproduto. 2012. 253f. Tese (Doutorado em engenharia de produção) - Universidade Federal de São Carlos, 2012. Disponível em: < http://www.bdtd.ufscar.br/htdocs/tedeSimplificado//tde_busca/arquivo.php?codArquivo=5418>. Acesso em: 20 maio 2014.

PAIVA, E. L.; CARVALHO JR.; J. M.; FENSTERSEIFER, J. E. Estratégia de produção e de operações: conceitos, melhores práticas e visão de futuro. Porto Alegre: Bookman, 2004. 
PINTO VIEIRA, A. C. et al. Proteção da biotecnologia na agricultura. CONGRESSO BRASILEIRO DE ECONOMIA, ADMINISTRAÇÃO E SOCIOLOGIA RURAL SOBER, 45., 2007. Disponível em: < http://www.sober.org.br/palestra/6/884.pdf>. Acesso em: 3 fev. 2013.

PIRES, S. Gestão Estratégica da Produção. Piracicaba: UNIMEP, 1995.

POZZOBON, D. M.; LÖBLER, M. L.; SILVEIRA, V. C. P. O processo de estratégia em empresas agropecuárias: proposição de uma metodologia de formulação e implementação. 2006, Fortaleza - CE: [s.n.], 2006. p. 1-20. Disponível em: < http:// www.ufsm.br/extrural/vicentepp/arquivospdf/o processo de estratégia.pdf $>$. Acesso em: 15 out. 2014.

RATHAMANN, R. et al. Uma proposta de estrutura analítica sistêmica para o estudo da decisão nos agronegócios. 2007. In: CONGRESSO BRASILEIRO DE ECONOMIA, ADMINISTRAÇÃO E SOCIOLOGIA RURAL SOBER, 45., 2007. Anais... Londrina, PR: Sober, 2007. p. 1-19.

RODRIGUES, R. O céu é o limite para o agronegócio brasileiro. Conjuntura Econômica, Rio de Janeiro, v.60, n.11, p.14-15, nov. 2006.

SANT 'ANA, E. J. Polos de aglomeração produtiva de milho, aves e suínos em Mato Grosso. 2010. Universidade Federal de Mato Grosso, 2010. Disponível em: $<$ http://www.ufmt.br/ufmt/site/userfiles/file/adr/Disserta\%C3\%A7\%C3\%B5es/Disserta\%C3\%A7\%C3\%A3o_EmersonJos\%C3\%A9.pdf> . Acesso em: fev. 2015.

SANTOS, I.; MACEDO, S.; RAMOS, T. Estratégias eficientes para empresa rural. São João Del Rei: [s.n.], 2008. Disponível em: < http://www.unifenas.br/antigo/extensao/administracao/viiicongresso/expandido05.pdf > . Acesso em: 05 set. 2014.

SILVA, E. M. O relacionamento entre estratégia de manufatura práticas de produção e desempenho operacional e de negócio: uma survey em firmas do setor moveleiro. 2008. 194f. Tese (Doutorado em Engenharia de Produção) - Universidade Federal de São Carlos, São Carlos, 2008. Disponível em: < http://www.teses.usp. 
br/teses/disponiveis/18/18140/tde-12112008-165833/pt-br.php> . Acesso em: 12 abr. 2014.

SLACK, N. et al. Administração da produção. São Paulo: Atlas, 1997.

SLACK, N.; CHAMBERS, S.; JONHSTON, R. Administração da produção. 2. ed. São Paulo: Atlas, 2008.

VIEIRA JUNIOR, P. et al. Análise da governança da cadeia da soja. p. 1-20, 2006. Disponível em: <http://www.alasru.org/wp-content/uploads/2011/12/28-GT-Antonio-Marcio-Buainaim-Vieira-Junior.doc > . Acesso em: 17 fev. 2014.

WHEELWRIGHT, S. C. Manufacturing strategy: defining the missing link. Strategic Management Journal, v. 5, n. 1, p. 77-91, 1984.

ZEN, S.; BRAGATO, I. R.; SPERS, E. E. Diversificação de atividades como gerenciamento de risco na agricultura. In: CONGRESSO DA SOBER, 43., 2005, Ribeirão Preto, SP. Anais... Ribeirão Prero: SOBER, 2005. p. 1-16. 2005. Disponível em: < http:// www.sober.org.br/palestra/2/662.pdf> . Acesso em: 17 fev. 2014.

ZYLBERSTAJN, D. Administração de sistemas de base agrícola: análise de fatores críticos. REAd, v. 48, n. 2, p. 203-207, 2013. Disponível em: < http://www.scielo.br/ scielo.php?script $=$ sci_arttext\&pid $=$ S0080-21072013000200002 $>$. Acesso em: 22 set. 2013.

Recebido em: 2016-02-17 Aceito em: 2017-03-24 